\title{
The stability of the wall of the main beam of the movable bridge (application of SP method)
}

\author{
Sergey Chizhov ${ }^{1}$, Artyom Pismak $^{2}$, Anatoly Antonyuk ${ }^{1 *}$ \\ ${ }^{1}$ Emperor Alexander I St.Petersburg State Transport University, 190031, Russia, Saint Petersburg, 9 \\ Moskovsky pr. \\ ${ }^{2}$ Lengiprotransput - a branch of Roszheldorproject JSC, 190031, Russia, Saint Petersburg, 117 \\ Naberezhnaja reki Fontanki.
}

\begin{abstract}
The objects of the article are: analyze the work of the main beams of the movable span of the drop-down system near the axis of rotation; analyze the stress-strain state of the main beams of the movable span of the drop-down system near the axis of rotation; analyze the acceptability of the normative methodology (SP) for calculating the stability of the wall of a continuous steel beam during the design and calculation of movable bridge of the drop-down system. A computationalmathematical model of the movable span of the drop-down system is developed in a modern computational software package based on the finite element method. The main disadvantages of the normative methodology (SP) for calculating the wall stability of a continuous steel beam which used in design and calculation of movable bridge of a drop-down system are presented.
\end{abstract}

\section{Introduction}

Today, in the design and construction of movable bridges of the drop-down system, the most commonly used welded metal beams the so-called main beams are interconnected by a covering sheet of an orthotropic plate of the carriageway and a system of through crosslinks. In such constructions despite their spatial work during which the static circuit also changes the most common method of strengthening the beam wall is to install stiffeners which can ensure the stability of the wall at the entire stage of wiring and aiming the wing of the movable span. Based on the analysis of the theoretical, theoretical, structural and technological features of the movable bridge designs under consideration it was found that there are a number of unexplored issues to improve the use and operation of movable bridges of the drop-down system, one of which is considered in this article:

- the existing methods for calculating local stability, in particular SP and SNiP, the walls of beams in the design of movable bridges of the drop-down system, as well as the peculiarities of the stress-strain state of the beam walls with and without radial stiffeners in the process of their spatial work - wiring and aiming of the movable, are incorrectly taken into account wings.

\footnotetext{
${ }^{*}$ Corresponding author: aaa.12.03.1992@mail.ru
} 


\section{Task description}

In the course of this study, it was necessary to solve the following tasks:

1) To develop the correct finite element model of the movable span of the drop-down system using a modern software package. In this study it was decided to use the modern SOFiSTiK software package.

2) From the obtained results of calculating the finite element model, analyze the local stress-strain state of the wall of the main beam of the movable bridge of the expanding system near the axis of rotation.

3) Compare the results of the analysis of the finite element model and the results of calculating the stability of the wall of the main beam of the movable bridge of the drop-down system near the axis of rotation according to the SP (SNiP) technique.

\section{Design features of movable bridges drop-down system}

Movable bridges of various systems play an important city-forming role in it's further development perspective. Also, movable bridges located in the central part of the city have, among other things, a kind of architectural expressiveness, which indicates their widespread use in the capital's and architecturally significant cities of the world.

On the example of the city of St. Petersburg, which cannot exist without bridges, in particular movable bridges, the federal transport river highway "Volga-Baltic Waterway named after V.I. Lenin ", the significance for the economic well-being of which is confirmed both by centuries-old history, and by intensive current navigation (Fig. 1).

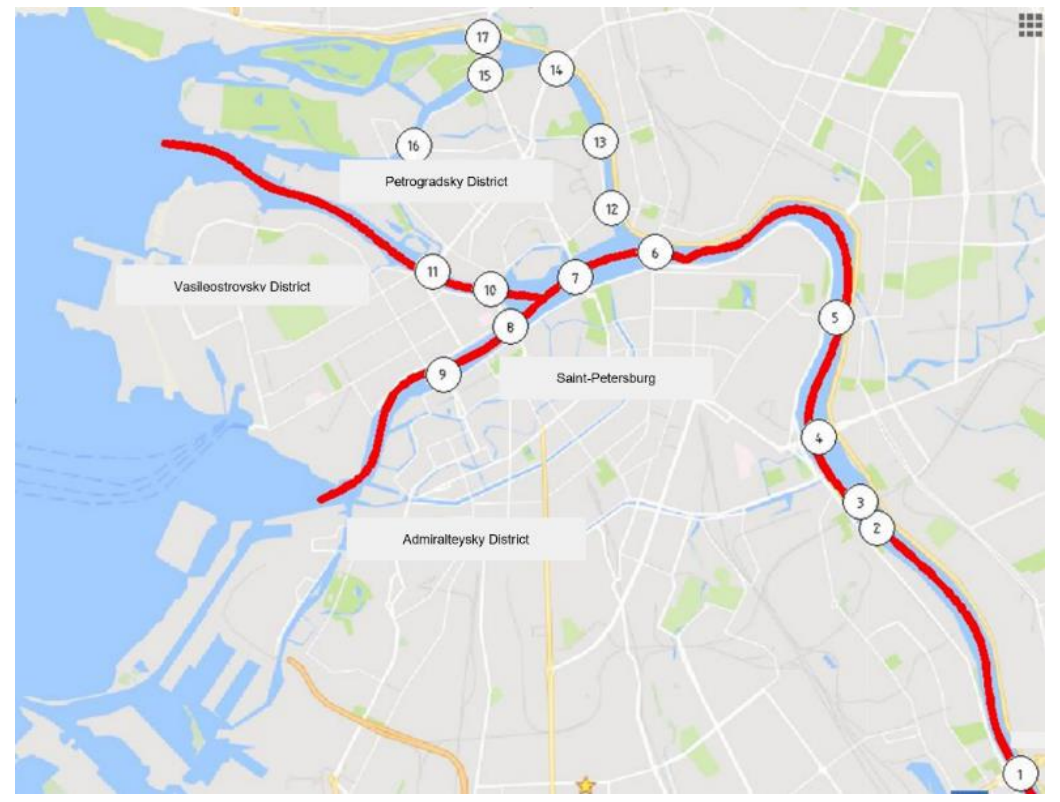

Fig. 1. The layout of movable bridges in St. Petersburg: 1 - Volodarsky bridge; 2 - Finland bridge the first way; 3 - Finland bridge the second way; 4 - Alexander Nevsky bridge; 5 - Big Okhtinsky bridge; 6 - Foundry bridge; 7 - Trinity bridge; 8 - Dvorcovy bridge; 9 - Blagoveshensky bridge; 10 - Birjevoy bridge; 11 - Tuchkov bridge; 12 - Sampsonievsky bridge; 13 - Grenadyorsky bridge; 14 -

Kantemirovsky bridge; 15 - Kamennoostrovsky bridge; 16 - Bolshoi Krestovsky bridge; 17 Ushakovsky bridge; ---- - fairway. 
Based on the foregoing it is clear that in St. Petersburg the majority of movable bridges have a drop-down system and also taking into account the fact that it's highly loaded bridges both in terms of transport and shipping on the Neva fairway we will consider in more detail this is a structural type of movable bridge. In general movable spans of the drop-down system and adjustable mechanisms consist of the following main components: an electro-hydraulic or electromechanical drive that provides a direct force effect on the movable spans during dilution and guidance of the wing; directly movable span (wing), consisting, as a rule, of the main solid-stepped metal beams; orthotropic plate; coating the external plate, perceiving force from a moving traffic stream; counterweights; rotation axis and unloading mechanism; locks; span bearings; power and control system. Figure 2 shows a scheme of a draw-span of a drop-down system with an unloaded axis of rotation using a swinging strut since in the future it will be this model that will be simulated in SOFiSTiK.

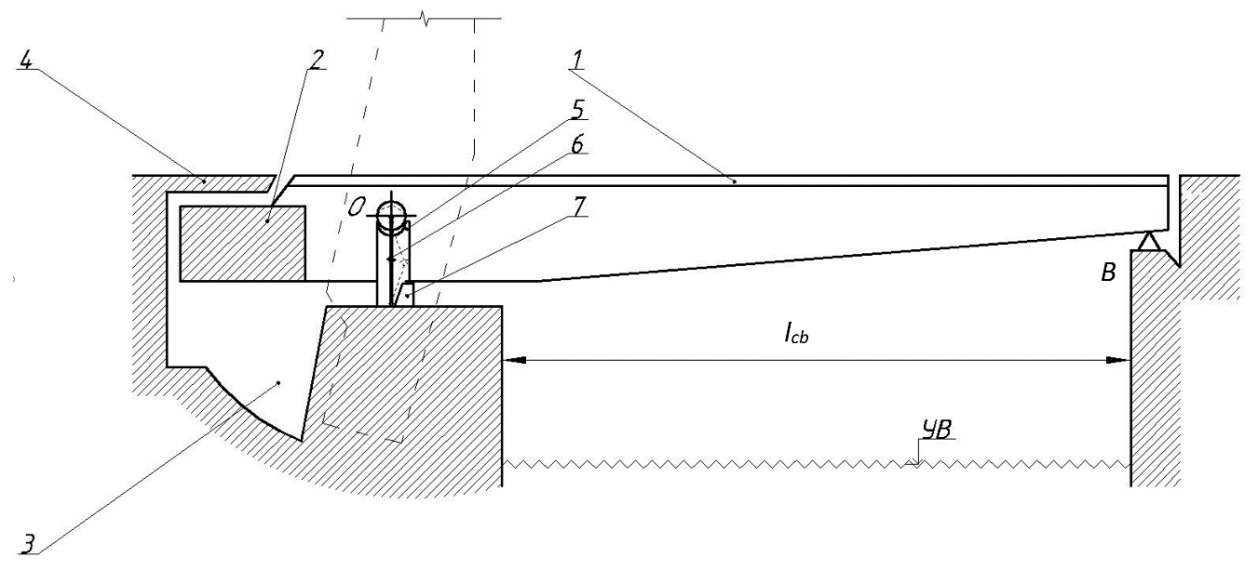

Fig. 2. Scheme of a single-wing movable bridge of a drop-down system with an unloaded axis of rotation using swinging struts: 1 - a swing wing, 2 - a counterweight, 3 - a counterweight well, 4 overlapping of a counterweight well, 5 - horizontal axis guides. 6 - swinging strut, 7 - lower support of the hinge of the swinging strut, $\mathrm{YB}$ - water level, $\mathrm{O}$ - axis of rotation, $\mathrm{B}$ - support of the movable span.

During the span wiring/guidance, it's spatial position and direction of action of the support reaction change. To this end to strengthen and ensure the required stability of the wall of the main beam 2, radial stiffeners are arranged near the axis of rotation (Fig. 3). The scheme of reinforcing the wall of the main beam using radial stiffeners presented in Figure 3 is by far the most common way to ensure the stability of the wall of the metal beam used in such designs of movable bridges. 

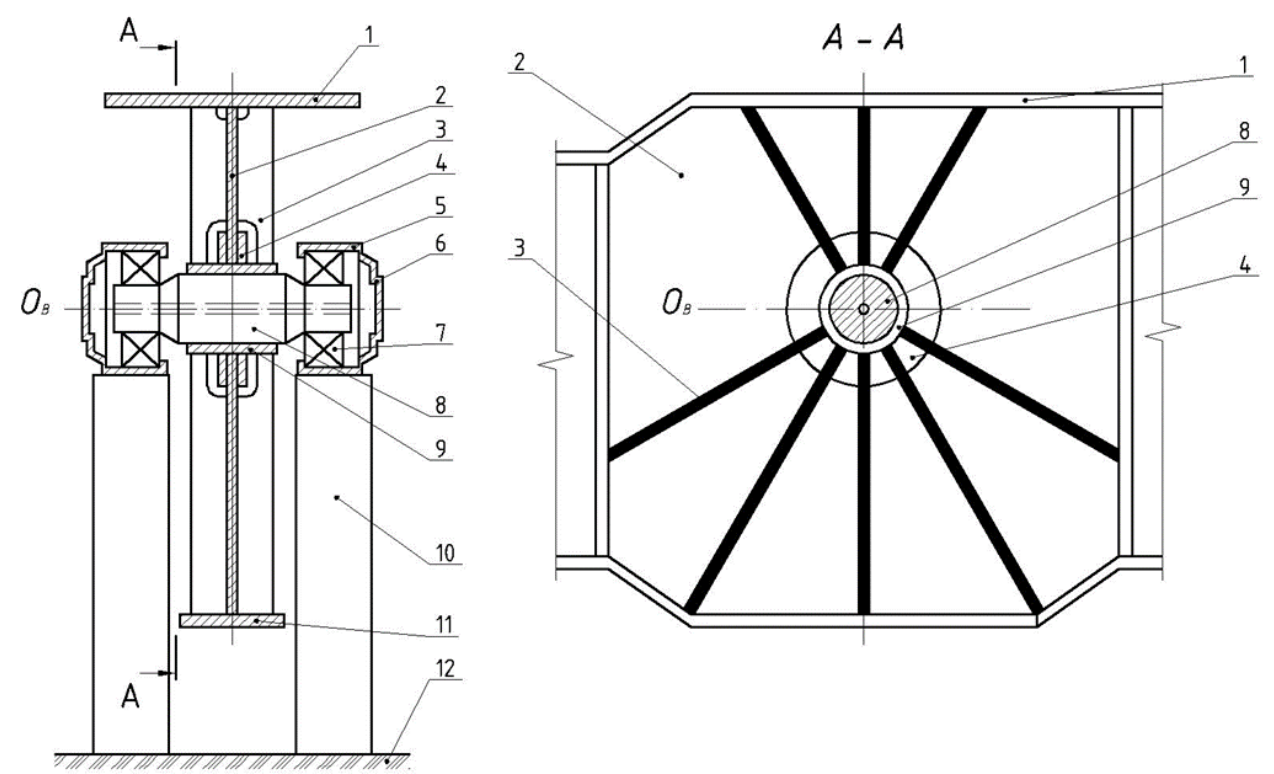

Fig. 3. Scheme of strengthening the wall of the main beam of the movable bridge of the bridge of the drop-down system near the axis of rotation: 1 - top sheet of the orthotropic plate; 2 - wall of the main beam; 3 - radial stiffener; 4 - annular diaphragm; 5 - bearing housing; 6 - covers; 7 - bearings; 8 - axis of rotation; 9 - tubular sleeve; 10 - a rack of the bearing of an axis of rotation; 11 - lower flange of the main beam; 12 - support movable span; $\mathrm{O}_{\mathrm{B}}$ - the axis of rotation.

\section{Construction of the finite element model of the movable span of the drop-down system}

The calculation model of the movable span of the metal road bridge is modeled by analogy with the Volodarsky bridge, located in St. Petersburg.

In the induced position, the span works according to the scheme of a single-console beam with a span of $45.2 \mathrm{~m}$ and a cantilever $12.56 \mathrm{~m}$ long, supported by a support. To unload the axis of rotation the mechanism of the swinging racks is used. The weight of the wing metal structures is 664 tons, the weight of the tail section with counterweights 1111 tons with a total weight of the span of 2060 tons, the design angle of the wing is $72^{\circ}$.

The following elements were used to build the finite element model: the wall of the main beam, the upper and lower zones, stiffeners - plate (shell) elements; cantilever elements of the main beam abroad of the study area - beam elements; orthotropic plate with stringers - plate elements; transverse beams - beam elements; the shaft is a volume element, the sleeve is a shell element (Fig. 4) [1, 2, 3, 4, 5]. All design deviations were also observed.

Between the surfaces of the shaft and the sleeve of the axis of rotation with the help of auxiliary elements and means of the PC SOFiSTiK preprocessor, spring elements were introduced over the entire width of the sleeve - elements with a certain final stiffness equal to the stiffness of the plate made of 10HSND steel - the material of the sleeve and shaft. To ensure the stability of the structure, the transverse stiffness of the spring elements was taken into account $-\mathrm{E}=2 \cdot 105 \mathrm{kPa}$. The spacing of the springs along the axis of rotation is calculated automatically according to the algorithm of the program - the radial step of the spring elements was $10^{\circ}$ (Fig. 5) [6, 7, 8, 9]. 
In the calculated finite element model boundary elements are modeled tied to the transverse beam near the axis of rotation which characterize the hydraulic lifting mechanism of the bridge layout (Fig. 6).

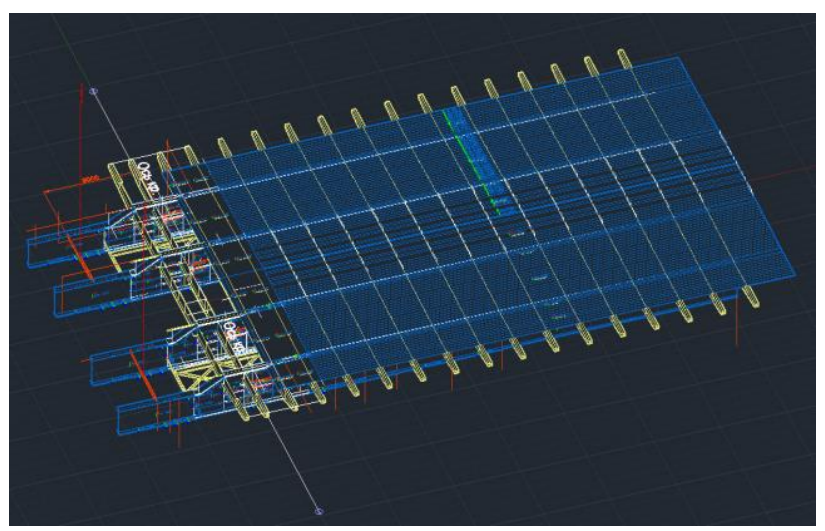

Fig. 4. General view of the finite element model

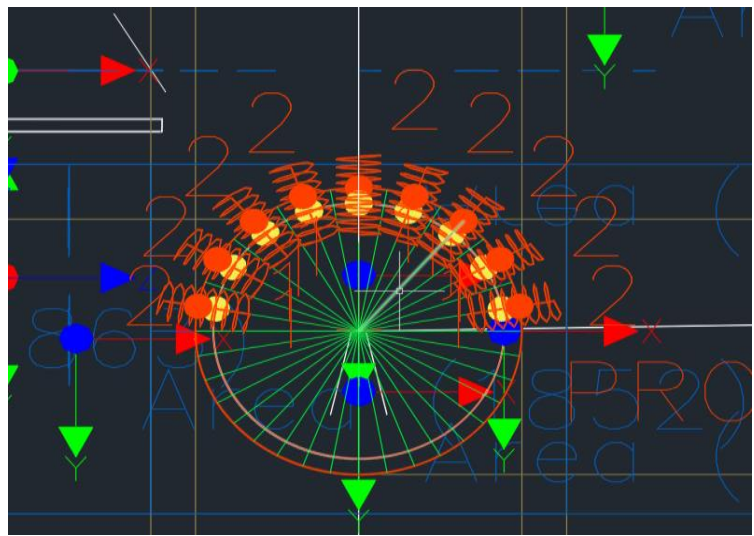

Fig. 5. Finite element model of supporting the main beam on the axis of rotation

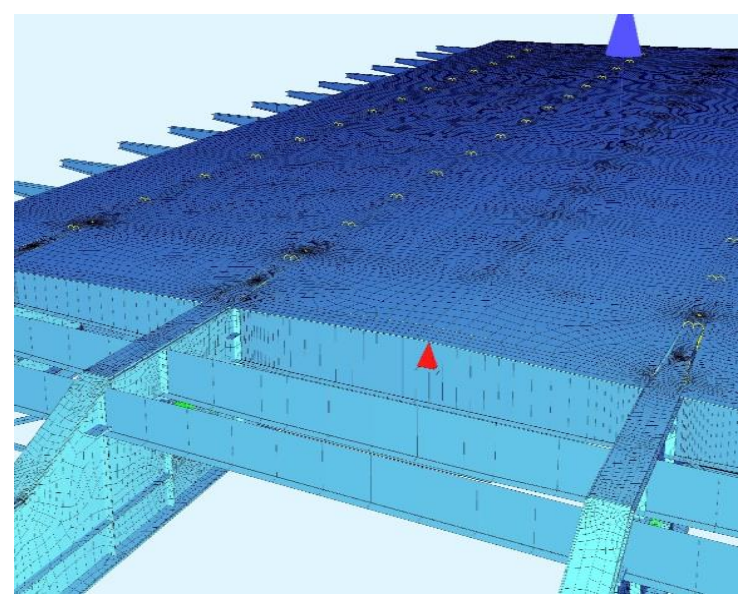

Fig. 6. Finite element model of the hydraulic lifting mechanism 
The calculation took into account the dead weight of the structure, the weight of the bridge canvas, walling and counterweight.

To create a simplified finite element model it was decided to cut the element from the structure and transfer internal forces to it from the cut off structural elements (Fig. 7). The impacts of the beam are replaced by the forces obtained as a result of additional calculation of the span where the node selected for further calculation (nodes for 4 beams) is excluded from the calculation, and at the ends of the beams a connection is made in the form of a hard seal in the places where the node section is excluded (Fig. 8) [10,11, 12]. In this case we calculate the scheme taking into account the rotation of the beam to determine all variants of forces.

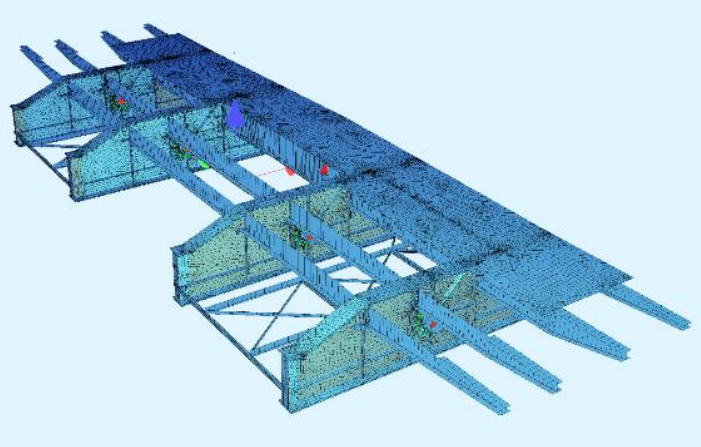

Fig. 7. Investigated structural element of the simplified finite element model

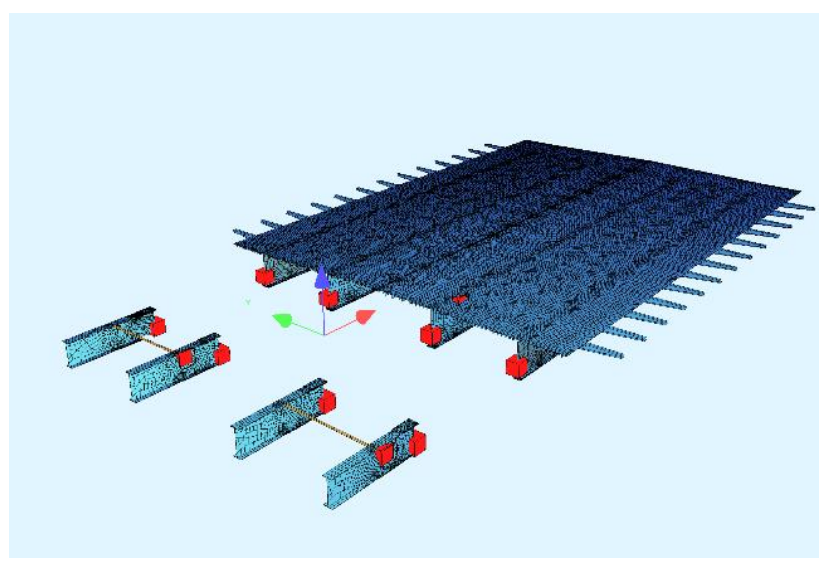

Fig. 8. Model element for determining the forces in the main beams

Further, in order to maintain the accuracy of calculations, a comparison was made of compressive stresses in the full model and in the loaded simplified model with the transfer of forces to the beam wall (Fig. 9, 10) $[13,14,15,16]$. 


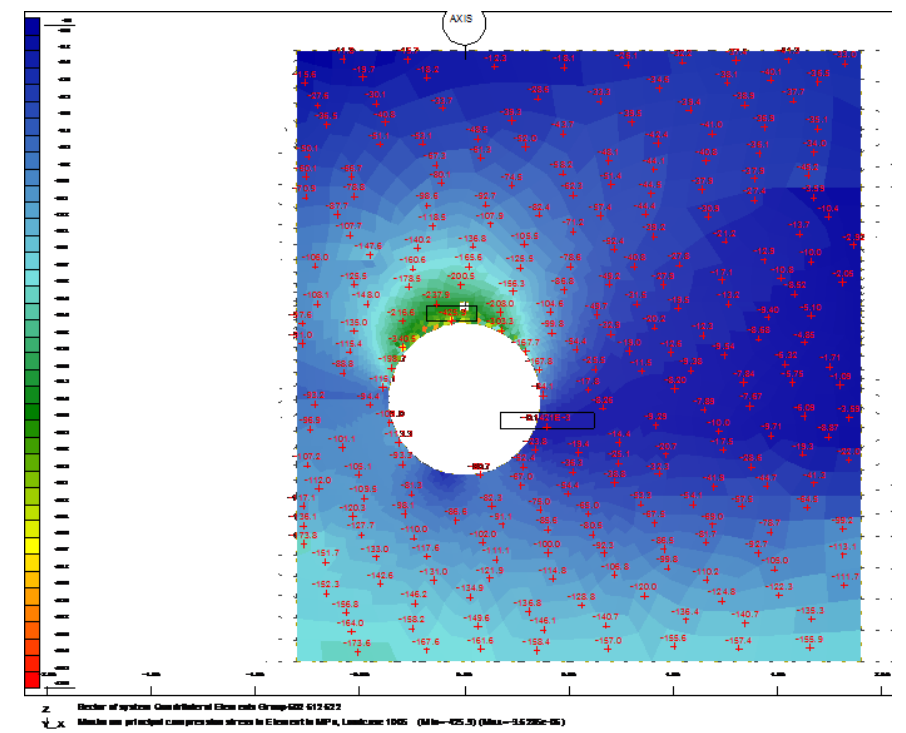

Fig. 9. Fields of compressive stresses in the wall of the main beam of the full finite element model

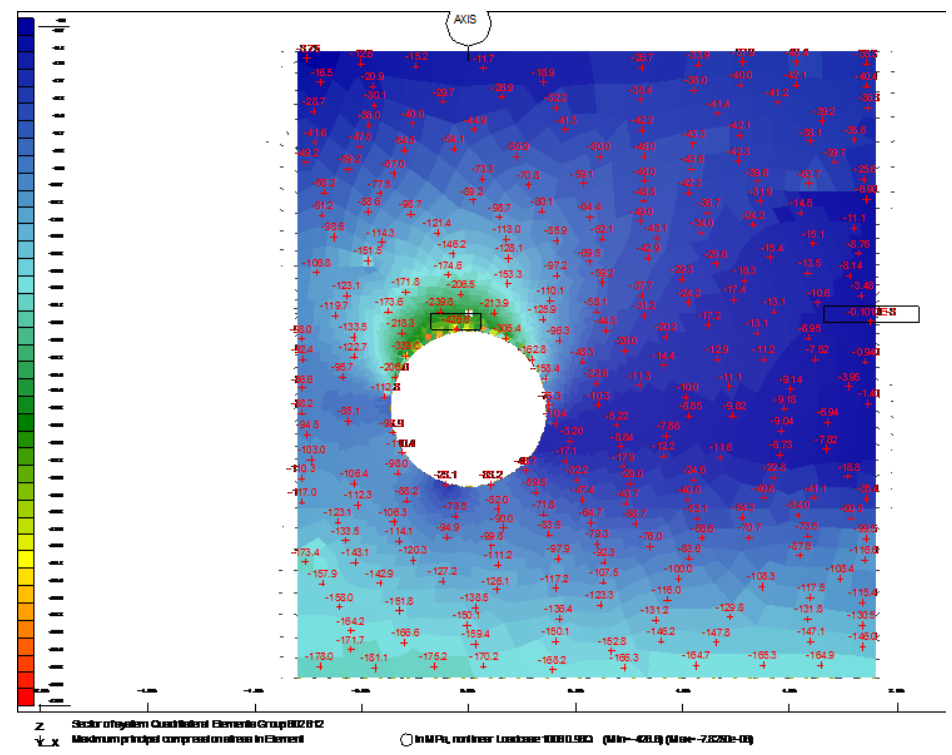

Fig. 10. Fields of compressive stresses in the wall of the main beam of a simplified finite element model

According to the calculation results it can be unequivocally stated that the accuracy of the calculations in the simplified model is acceptable within $1 \%$.

\section{The calculation of the stability of the wall of the main beam near the axis of rotation by the method of SP (SNiP)}

The calculation is carried out according to p. 8.44 in SP 35.13330.2011 for a cross-section of type "c" (Fig. 11). The calculation is carried out according to the theory of prismatic folded shells. 
To ensure the stability of the wall with the dimensions of a given flange the condition must additionally be fulfilled:

$$
h / t \leq 0.951 \cdot \alpha /\left(\sigma_{x, c r, e f} / E\right)^{0.5}
$$

where, $\sigma_{x, c r, e f}=\sigma_{x} \cdot m$ - reduced critical stress, at $m=0.9$, moreover it is necessary that $\tau_{x y} \leq 0.2 \sigma_{x}$.

$$
\alpha=(1+3.10 /(3 \vartheta+4)) \times\left(0.405+0.085 \cdot \xi^{2}\right) 0.5
$$

In equation 2 the parameter $\xi=1-\overline{\sigma_{x}} / \sigma_{x}$, where, $\overline{\sigma_{x}}$ - min stress, a $\sigma_{x}$ - max stress.

In this calculation the stress was considered according to the data obtained from the software package $\left(\overline{\sigma_{x}}=11 \mathrm{M \Pi а}-10 \mathrm{~mm}\right.$ from the top of the beam; $\sigma_{x}=321 \mathrm{M \Pi а}-10$ $\mathrm{mm}$ from the sleeve).

$$
\vartheta=\vartheta_{3}=\beta_{3}^{3} \cdot\left(1 /\left(1-\beta_{3}^{2} \cdot \alpha_{3}^{2}\right)\right)
$$

где, $\beta_{3}=t / t_{n}=12 / 64=0.1875$;

$\alpha_{3}=b_{n} / n=0.325 / 1.190=0.273$;

$\xi=1-\overline{\sigma_{x}} / \sigma_{x}=1-11 / 321=0.9657$.

Substituting the obtained values into equation 2 we obtain the value of the parameter $\alpha=1.21$. Next we verify the fulfillment of inequality 1 :

$99.17 \leq 0.951 \cdot 1.21 /(444.8 / 206000)^{0.5}$;

$99.17 \leq 24.76$.

Value $\sigma_{x, c r, e f}$ depends on the $\sigma_{x}=321 \mathrm{M \Pi a}$ (equation 8.23 in SP 35.13330.2011 at E $=2.06 \cdot 105 \mathrm{MPa}$ ). The condition is not satisfied. Installation of stiffeners is required.

The calculation scheme is shown in Figure 7. We leave the maximum and minimum voltage values - obtained as a result of calculating the finite element model. All calculations are carried out according to the same methodology from SP 35.13330.2011.

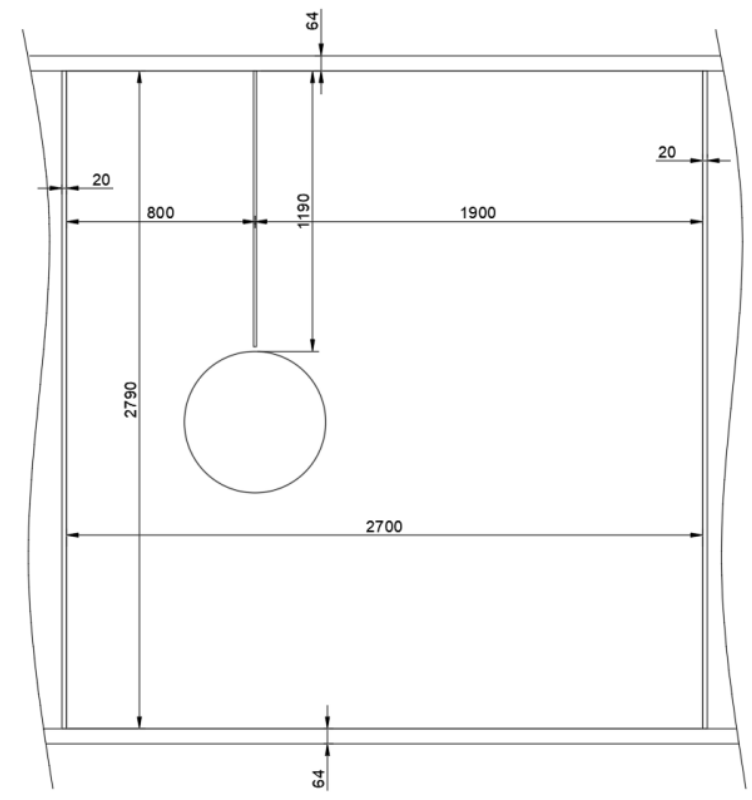

Fig. 11. The calculation scheme of the wall of the beam movable span near the axis of rotation 
As a result of the calculation, verification of compliance with all necessary conditions was not performed $(\mathrm{K}=\mathbf{4 . 0 8}>1.0)$.

\section{Conclusions}

The disadvantages of the methodology SP 35.13330.2011:

1) When calculating the beam the latter is considered in a horizontal position which implies the selection of stiffeners exclusively in the horizontal or vertical direction which is valid for calculating the beams of the movable span only when it is opened $0^{\circ}$ and $90^{\circ}$ according to p. 8.44 in SP 35.13330.2011.

2) The distance between the stiffeners cannot be rationally determined when turning the beams and opening them. For example, the geometric parameter "a" needs to be determined differently since according to Figure 8 it's value is not constant, and a change in the methodology for it's determination casts doubt on the rationality of applying equations with empirical coefficients (eq. X.11 in SP 35.13330.2011 and others).

3) The calculation equations for determining the stresses $\sigma_{x}, \sigma_{y}$ and $\bar{\sigma}_{x}, \bar{\sigma}_{y}$ (eq. X.1 and X.2 in SP 35.13330.2011), as well as for determining critical stresses (they are the critical reduced stresses calculated according to eq. X.11, X.12, X.13, etc.) are not applicable in special cases to the calculation of movable structures since the forces applied to the design scheme and the equations themselves do not take into account the spatial position of the structure when turning around the axis of rotation.

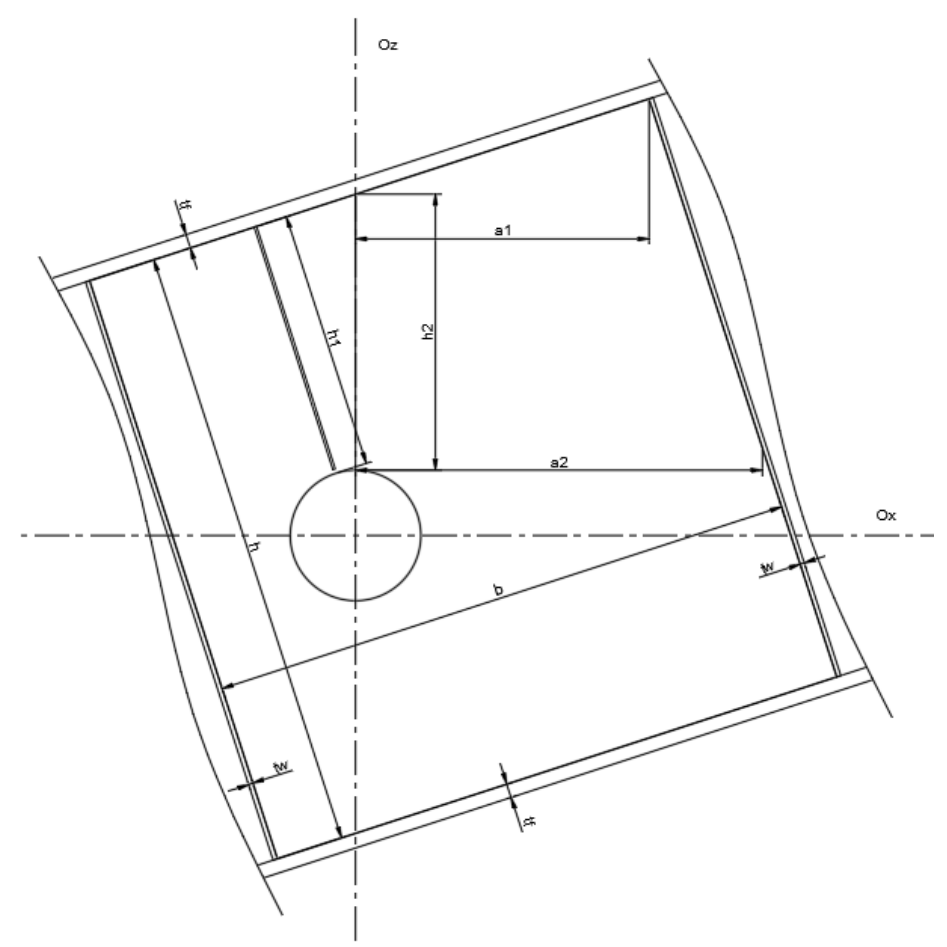

Fig. 12. Changing the values of the geometric parameters of the calculation scheme scheme due to it's spatial work 


\section{References}

1. F. Papp, Engineering Structures, 106, 124-136 (2016).

2. J. Jönsson, Thin-Walled Structures, 33, 245-268 (1999).

3. J. Jönsson, Thin-Walled Structures, 33, 269-303 (1999).

4. Z. Kala, Procedia Engineering, 57, 504-514 (2013).

5. Z. Kala, Archives of Civil and Mechanical Engineering, 15, 1098-1107 (2015).

6. H. Pasternak, G. Kubieniec, Journal of Civil Engineering and Management, 22(1), 4755 (2016).

7. P. Panedpojaman, W. Sae-Long, T. Chub-uppakarn, Thin-Walled Structures, 99, 182194 (2016).

8. J. Valeš, Z. Kala, J. Martinásek, International Journal of Mathematical and Computational Methods, 1, 103-108 (2016).

9. J. Melcher, Z. Kala, M. Holický, M. Fajkus, L. Rozlívka, Journal of Constructional Steel Research, 60, 795-808 (2004).

10. Z. Kala, Journal of Civil Engineering and Management, 15(3), 299-307 (2009).

11. Z. Kala, Journal of Civil Engineering and Management, 22(3), 417-424 (2016).

12. Z. Kala, Journal of Civil Engineering and Management, 21(7), 902-911 (2015).

13. A. Milenin, R. Kuziak, M. Lech-Grega, A. Chochorowski, S. Witek, M. Pietrzyk, Archives of Civil and Mechanical Engineering, 16(1), 125-134 (2016).

14. A. Taras, R. Greiner, Journal of Constructional Steel Research, 66(5), 648-663 (2010).

15. A. Rebelo, N. Lopes, L. Simões da Silva, D. Nethercot, P.M.M. Vila Real, Journal of Constructional Steel Research, 65, 818-831 (2009).

16. J. Atkočiūnas, T. Ulitinas, S. Kalanta, G. Blaževičius, Engineering Structures, 101, 352-363 (2015). 